\title{
THE ANALYSIS AND INTERPRETATION OF AERIAL PHOTOGRAPHS IN SOIL SURVEY AND LAND CLASSIFICATION ${ }^{1}{ }^{2}$ )
}

\author{
P. BURINGH Documentatie
}

Lecturer in soil science and pedological interpretation of aerial photographs, International Training Centre for Aerial Survey, Delft, The Netherlands

\section{SUMMARY}

During the last few years the writer has made a thorough study of the possibility of applying vertical aerial photographs to soil survey and land classification. As a consequence of this study a new method was developed the so-called pedological analysis of aerial photographs, which opens up fresh perspectives for soil mapping in various countries. The production of soil maps and land classification maps can be greatly speeded up with the aid of systematic pedological photo-analysis. In most cases the field work can be reduced to $1 / 4$ or even less of the normal amount, while at the same time the result is more accurate. The pedological photo-interpretation makes it possible to produce reconnaissance soil maps of large territories quickly and efficiently. For very vast areas where researches must still be carried out aerial photography offers great possibilities, which are discussed below in greater detail.

\section{INTRODUCTION}

It is more than 30 years since Cовв (1923) drew the attention of soil surveyors to the fact that aerial photographs might present an important expedient for soil mapping. Since than much has been changed, not only in the technique of soil mapping, but also in aerial photography and its application. The progress in aerial photography and in the instruments for interpretation of the photographs and in the execution of measurements is such, that important perspectives are opening for the soil scientist, the land classification expert and the soil conservationist.

In many countries vertical aerial photographs or aerial photomosaics are used as basic maps for the field work (StEPHENS, 1953 and Soil Survey Staff, 1951). As aerial photos show more details of the terrain and as also the vegetation and the relief are clearly visible through the stereoscope, an orientation on these photos is much easier than on a map. Consequently, the marking of data on the photo can be done more accurately and quickly. Contrary to a map on which all objects are indicated by means of their specific symbols, the photo gives a true view of every object on the ground and of the forms of the earth's surface. When using air photos it must be possible to identify these objects; one should be able to read the air photos. This can quickly be learned, because in the field the photo can be compared with reality. To this end the use of a pocket stereoscope is recommended.

On many air photos phenomena can be observed, which might be of great importance to soil science; this has led to air photo interpretation. The success of such interpretations depends largely on the knowledge and ability of the photo-interpreter and on the complementary and controlling field research work which has been carried out. The results thus obtained usually concern the identification of the parent material in which the soil profile is developed

1) Sce previous article published in this review by the same author (Buningh, 1953).

2) Received for publication January 21, 1954. 
(Frost and Woons, 1946, 1948). It is obvious, however, that no photo is properly interpreted if the phenomena visible on it are only used for theoretical discussions about the origin of the soil or about the formation of the parent material (von Frytag Drabie, 1951). Such remarks can just as well be made in connection with the image of a soil map or in the field, they are not peculiar to aerial photographs. This kind of interpretation is no aerial photo interpretation in the sense in which we understand this; it is an interpretation of the result of a pedological research.

Modern soil survey and soil classification are based on the study of the soil profile. This study is executed partly in the field and partly in the laboratory. In the latter case samples of all horizons and layers of typical profiles are analysed, in order to get to know their physical, chemical and biological characteristics. It is clear that aerial photographs will hardly be used for this work.

The possibilities of the use of aerial photos can be found in quite a different sphere, viz. in that of the pedological photo analysis; this is a new application which is important for soil and land classification. The aerial photos contain much valuable information as regards the physical condition of the earth's surface. As far as they are of interest to soil science, these data may be analysed. For this air photo analysis many elements must be considered; they can be studied and handled either separately or in groups. The result is a large number of soil boundaries, which can be marked on the photo with very great accuracy. The subsequent soil mapping units show the factors in which they differ and those which they all have in common. Naturally, this only applies to those features which are indispensable for the analysis. This work, which every soil surveyor can learn, must be carried out systematically, as it is based on exact and measurable data; the result is a geographical analysis on a pedological basis (Buringir, 1953).

The pedological photo analysis must be considered as a tentative study of a soil map of which many important data are already known. The time which a soil scientist trained in photo analysis needs for this work is short compared with the duration of normal field work. With the aid of aerial photo-analysis field research can be carried out much more quickly and accurately. The saving of time is mainly due to the fact that many field observations which are otherwise neccessary for determining the location of the soil boundaries have now become superfluous. Those boundaries which cannot be determined at all, or only inaccurately, by means of aerial photo-analysis, must be traced in the field. For all mapping units a check must be carried out in the field in order to classify them properly. During the photo analysis a program for efficient field work may be set up to ensure that profile observations can be carried out at the most typical points. Another advantage is that this systematic method can also be applied to domains unknown to soil survey, which is not possible with air photo interpretation.

This method of air photo analysis is not only important for soil classification, but also for land classification, agricultural engineering, soil erosion surveys, soil conservation, highway engineering, geography, land use planning, geology, urban planning and many other sciences, (CoLwelt, 1952) where data of the physical condition of the earth's surface are used. Much progress has already been made in highway engineering, which deserves the attention of soil scientists (Frost, 1952, S Mitu, 1943, 1952, 1953, Colwell, 1952). 
A third application of aerial photos to soil science is pedological air photo interpretation. Here two methods can be distinguished viz. that of interpolation and that of extrapolation. Both are only applied to the reconnaissance soil survey and the general land classification. With the method of interpolation certain strips of the terrain in question are normally examined, i.e. photoanalysis in combination with field research, while the strips in between are treated by aerial photo-analysis only. This, combined with the experience gained from the total research, makes it possible to produce within a short time soil or land classification maps which satisfy reasonable requirements.

The extrapolation method can only be applied to surveys for orientation purposes. Here the interpreter's pedological experience obtained with other researches in similar terrains is of great assistance for the research of the areas photographed; afterwards a very general field for the purpose of orientation is carried out. Even this produces interesting results, as is proved by the work of REED (1951) in Liberia.

These two methods of pedological air photo interpretation have nothing to do with the pedological considerations about the result of the research. Such remarks may be made at the end of any pedological research, even if no aerial photographs have been used.

\section{PRinciples OF PHOTO-ANALYSIS}

An air photo analysis is carried out by identifying objects and patterns which represent soil mapping units and at the same time by the precise marking of the boundaries between these units. The importance of this analysis depends on the kind of characteristics on which the boundaries and units are based. There are, for instance, certain elements of aerial photo-analysis which point to great differences in the soil condition, whereas others indicate slight differences. To the first category belong land forms and slopes, to the second the differences in vegetation. During separate photo-analyses of a few elements the same boundaries very often come to the fore. This is an indication that the mapping units in question differ in some characteristics, which makes this analysis more valuable.

The possibilities of aerial photo analysis depend especially on the quality of the aerial photograph, which is influenced by many factors, such as the scale of the photographs, the camera, the film material, the weather conditions before and during the aerial survey etc. The nature of the area to be analysed also plays an important role. We shall not go into the details of all these features, although they are very important for the practical execution of an analysis. The technique of air photo analysis has to be learned in order to fully exploit the photographs. The analysis is carried out by means of some measuring instruments and a good stereoscope, provided with an excellent binocular $(5 \times$ enlargement).

The mapping units obtained by means of pedological photo analysis are chiefly soil associations, soil complexes and soil phases. Various soil phases, such as soil slope and erosion phases can be plotted quickly and accurately by means of measurements during the analysis. When the soil is classified, there are sometimes features which cannot be found on the photograph, e.g. lime content, colour of subsoil etc. ; they can only be plotted with the aid of normal field work. In general it will not be possible to irlentify on the photo- 

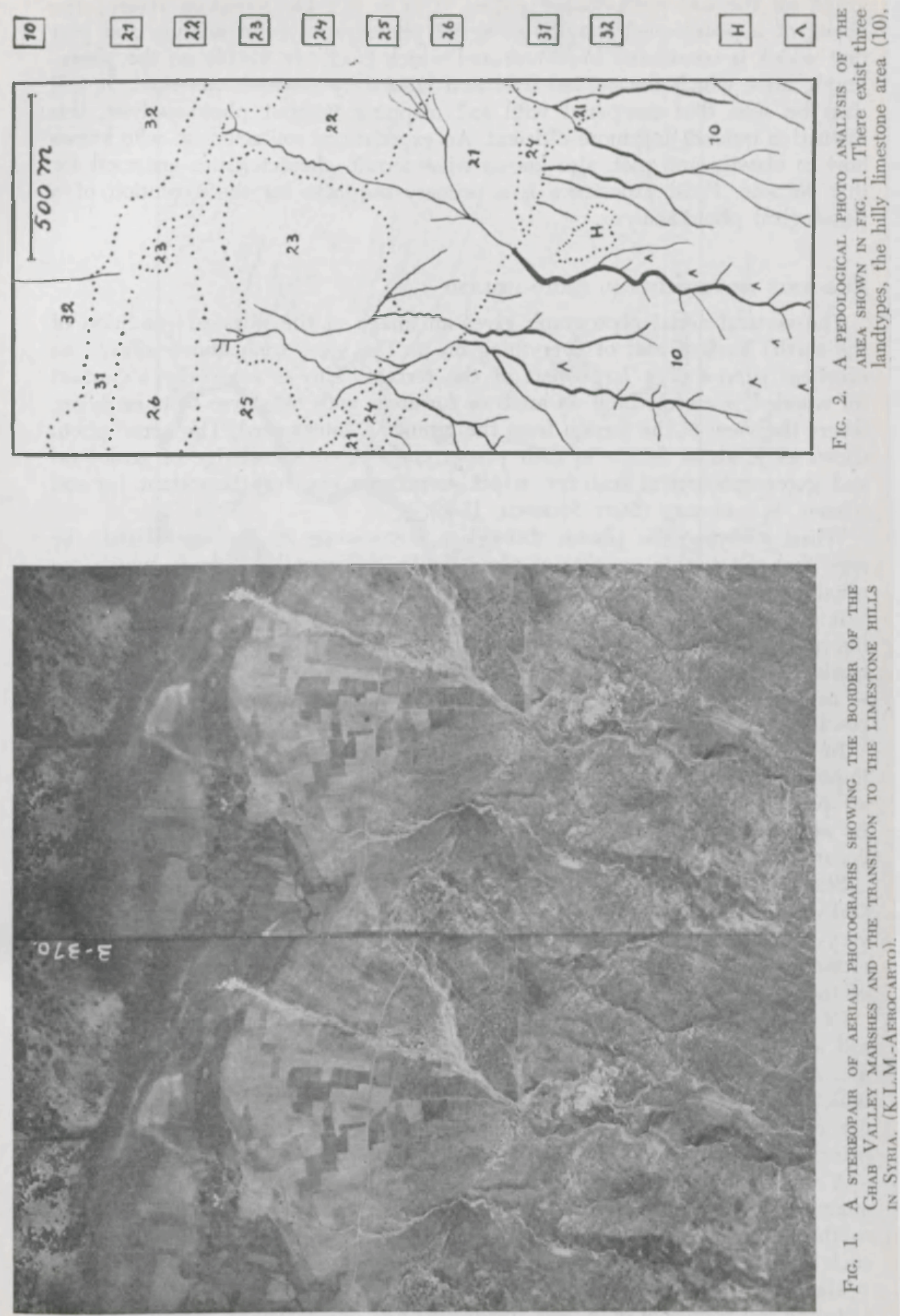

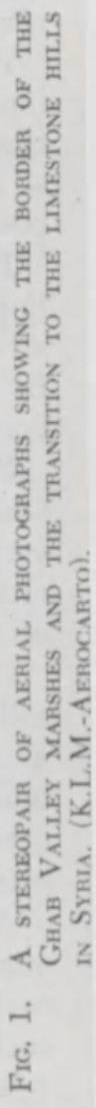


graph all the soil units to be plotted. This is not the intention either; the object of a pedological analysis of aerial photographs is to analyse and plot that which is considered important and which is clearly visible on the photograph, after which the normal field and laboratory research can start. It will then be seen that compared with soil mapping without photo-analysis, this method is quicker and more efficient. An experienced soil scientist, who knows how to classify and plot, also knows what terrain characteristics are used for this purpose. Field experience is a primary requisite for the execution of a pedological photo-analysis.

\section{Elements of PEDological Photo-ANalysis}

The vertical aerial photograph gives an image of the physical condition of the earth's surface and of everything on it. The view from above affords an excellent survey of a large, part of the terrain. This is especially important for wooded or closely built-up areas or for areas with hills, tree belts or dykes, where the view of the terrain from the ground is interrupted. The aerial photo shows all kinds of details in their proper connection. Knowledge of geological and geomorphological features, which sometimes are very important for soil science, is necessary (SMIT Siebinga, 1948).

When studying the photos through a stereoscope it can immediately be seen that the terrain consists of some totally different land types, which are usually identified by the difference in shape and relief.

It is clear that in the valleys, at the foot of the hills, on the slopes and on the plateaus different soils occur. These land type units can be very accurately marked on the photograph; at the same time it can be seen which units - as regards the analysed features - are similar. (BELCHER, 1950, has also pointed this out).

In many flat, alluvial areas the process of sedimentation often plays an important role. The soil genesis is closely linked up to this, so that also on air photos in many seemingly flat territories many units may still be plotted. In arid areas with saline and alkaline soils very distinct differences often occur, which are easy to analyse.

Similarly the hydrological condition of soils also lends itself well for analysis. Gully and drainage patterns which must usually be plotted completely, often vary greatly in land types where the soil conditions also differ largely. For an erosion survey it is important that the erosion types, the extent and intensity of the soil erosion be analysed.

Of the soil phases, it is particularly the soil thickness, the soil erosion, the soil slope and the soil drainage phase which play a significant role: Burned and silted phases can also very often be clearly identified. The measurements which are necessary for establishing the various soil slope phases, can be carried out during the air photo reading. To this end one must master the principles of photogrammetry.

A number of important elements used during the pedological air photoanalysis have already been mentioned. Considering their very close relation to the features which influence the soil profile development, an analysis of such elements usually produces a correct and valuable result.

The natural vegetation cover of an area may contain important indications as to the soil condition (v. D. EYK, 1953, v. D. EYK and Hendriks, 1953). A photo- 


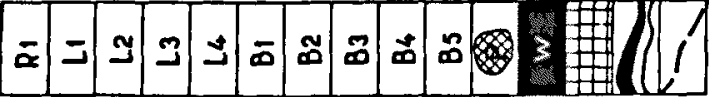

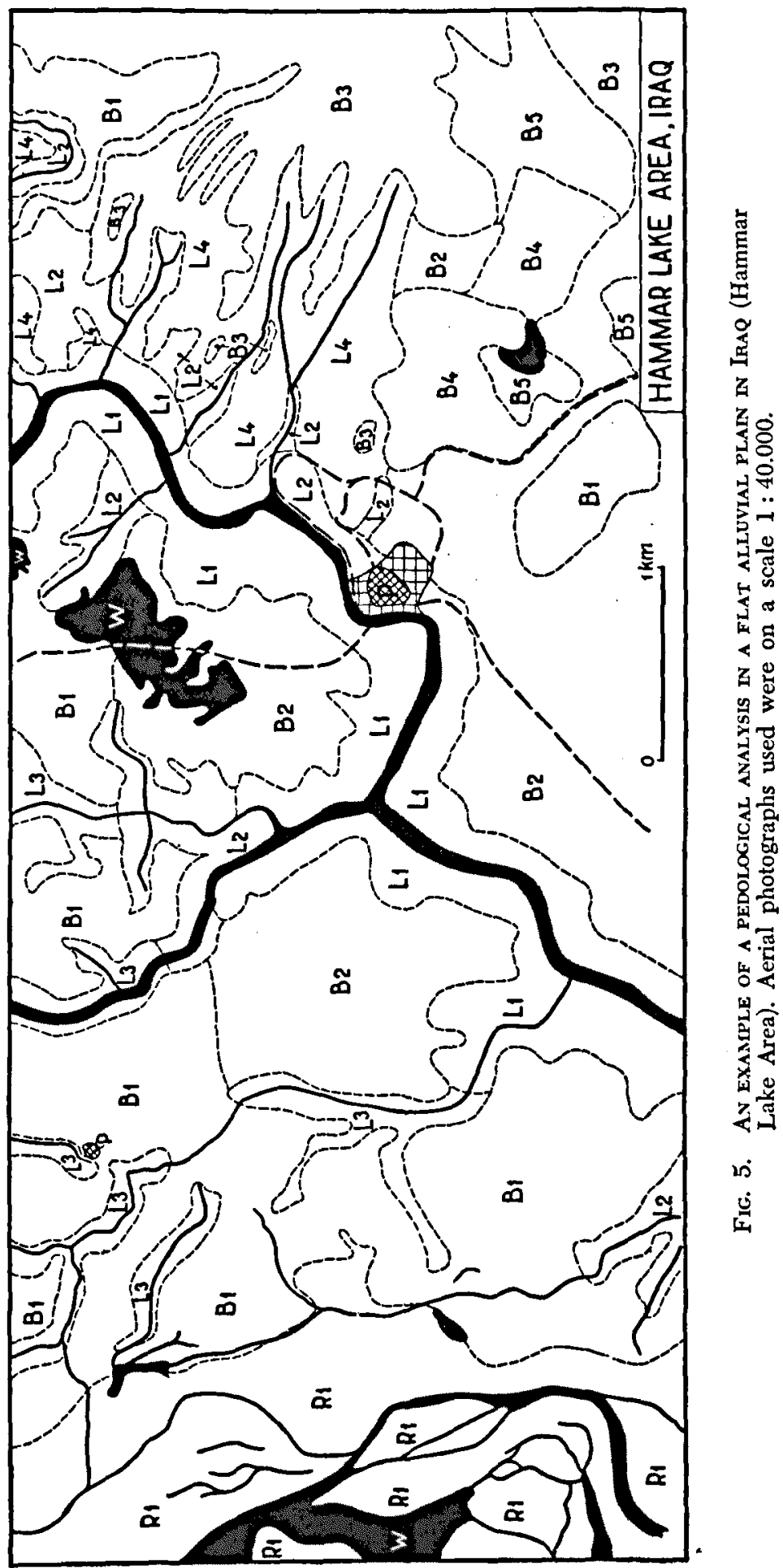


analyst must learn to identify characteristic vegetation types, for instance types which indicate saltish or brackish water conditions, dry or humid conditions, etc. For this purpose photo keys of well-known vegetation types are important (ANonYMous, 1945). Very often the most striking variations in the vegetation are of little pedological significance. An interesting example of this is given by Wieslander and Storie (1953). Furthermore, there are a large number of elements which relate to geographical and agricultural features on aerial photographs which may be of importance, especially in cultivated areas with an intensive land use.

Besides the elements which are always indicative of differences in soil conditions, there are others which only sometimes relate to differences. The first kind is most important and is therefore always used for photo analysis.

For clearness'sake, fig. 3 shows an example of a pedological photo analysis. Maps 1-6 represent the results or six separate analyses. In practice, however, such a map is made in one operation, of which map 7 and 8 are an illustration. Map 7 shows on how many maps the various boundaries occur. Thus the bounded mapping units are, with respect to certain factors, either identical to or different from each other.

The boundaries which only occur once are, in this example, based on vegetation differences, which in this case is of rather doubtful value. Map 8 represents the final result of the analysis. With these data at our disposal, the field work can be greatly simplified.

An example of an analysis in a flat area is given in fig. 5. For the production of a pedological photo-analysis many elements are needed. The analysis of the land types mentioned in this article necessitated the use of some twenty five different elements.

A special advantage of photo-analysis is the great topographic accuracy of the plotted soil boundaries. It usually is much greater than can be obtained in the field. The pedological details of the map do not reflect this.

\section{The application OF PHOTO-ANALYSis}

As already mentioned, the photo-analysis method may also be applied for many other purposes. For soil mapping the analysis actually consists of two parts, viz.

a) the analysis of the boundaries;

b) the classification of the mapping units resulting from the analysis.

It must be borne in mind that many important pedological features have not yet been considered; this because not all factors show on the photo, nor can they always be deduced from it.

Thus the units considered identical in the analysis need not necessarily be the same units on the final soil map. From this it follows that in any case all units of the photo analysis must be studied and classified in the field.

When carrying out the photo-analysis the possibilities and limitations which the photos offer may well be taken into account. Good air photos, taken on a scale of $1: 20.000$, usually afford the possibility of producing a soil map on a scale of $1: 50.000$ or one inch to a mile.

For soil maps on a smaller scale and with aerial photographs on the scale of $1: 40.000$ - provided they are of good quality - those elements are usually analysed which refer to the aim for which the soil map is being made. Here the same technique is applied as for field work. 

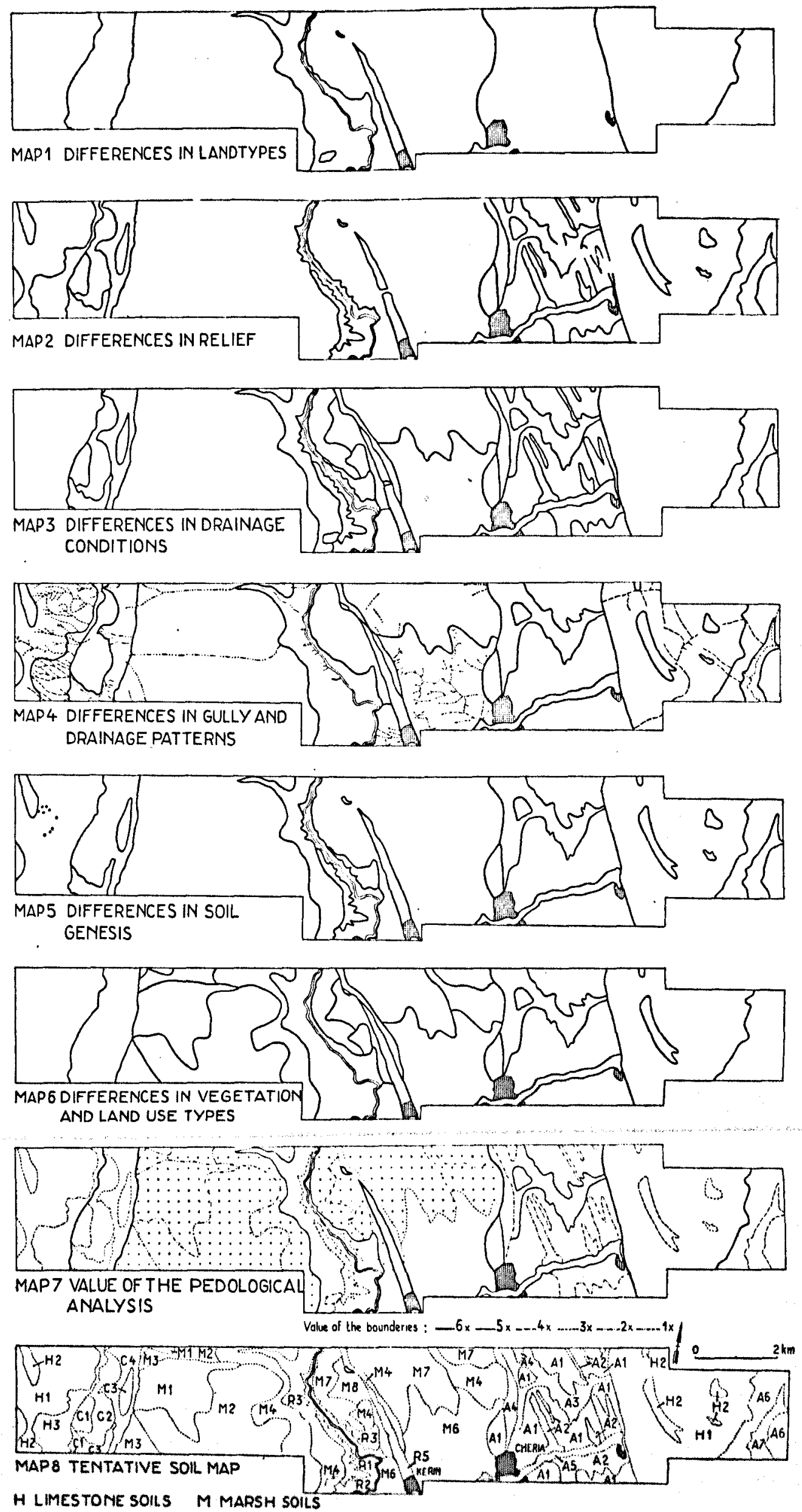

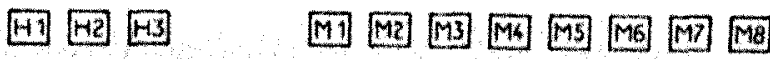

C COLLUVIAL SOIS R RIVERLEVEE SOILS A ALLUVIAL TERRACE SOLS

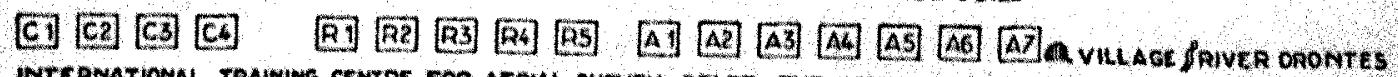

INTERNATIONAL TRAMIMG CERTRE FOR AERIAL SURNEY, DELTT, THE NETHERLAAMS, DO IA RBURINGH TOSS

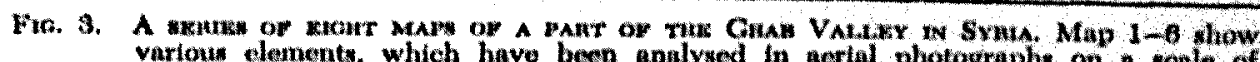
varioum elements, which have been analysed in aeriat photographe on a venle of 1:20.000. Map 7 gives the value of the pedologteal analysis. The boundurien tho find factors analysed in the aerial photographs.

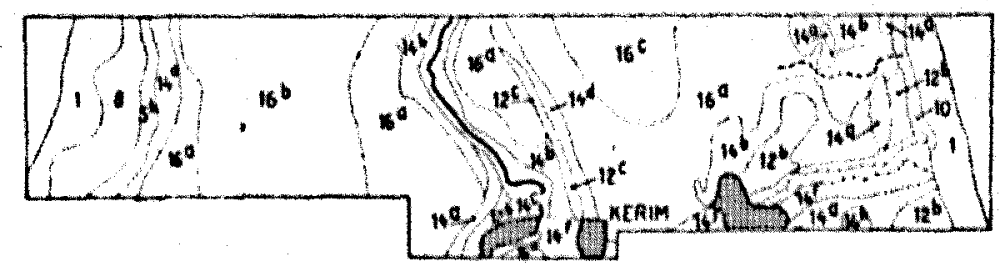

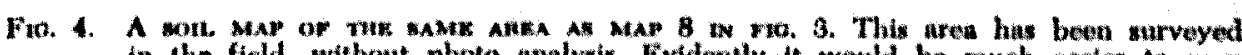
in the field, without photo analywir. Evidently it would be much easier to map the same area ant having made peololoical analysis.

(hy coures of the Hanue, Dwark, isution for the isation for the reclamation of the waste lands, Arnhem; Soll survey by Dr. K. 
classification and soil erosion, the number of experts is too small. Bearing in mind that, for instance in the U.S.A. alone (Alaska included) soil maps for 2.200 .000 sq. miles have still to be made, that 430 soil scientists and 50 soil chemists could work on this job alone for a period of 30 years, it is clear how much is still to be done (Simonson, 1952, Pasto, 1953). The costs involved are estimated at $\$ 158,000,000$. At the present time 130 soil scientists are employed in the U.S.A., while the annual outlay amounts to abt. $\$ 1,750,000$. When it is considered that this applies to a country where soil survey was started 53 years ago and that there are still many other countries where little or nothing has yet been done, all further comment is superfluous. Not only is it impossible greatly to increase the number of experts within a short time, but there are also financial restrictions.

To our mind the significance of the pedological analysis of aerial photographs lies in the introduction of a new technique for soil mapping. This method considerably increases the performances per expert and at the same time greatly decreases the expenses of the research per surface unit.

Our experience so far is that by means of airphoto analysis a soil survey on a scale of 1:50.000 may be carried out in about a quarter of the time necessary without the use of aerial photographs. The working capacity by means of this technique may be put at from 800 to 1000 hectares per working day.

\section{THE INTERPRETATION OF AERIAL PHOTOGRAPHS}

It is usually expected of the pedological interpretation of aerial photographs that a thorough study of the photograph will enable the soil condition of the terrain to be deduced and plotted. This, of course, is practically impossible; in order to know the soil condition, other data than those provided by the aerial photograph are needed. Very often the soil itself is not visible on the photograph, because it is grown over.

A pedological air-photo interpretation can only be executed in areas of which the soil condition in large parts is exactly known through an air-photo analysis and through research in the field and laboratory. For those parts which have not been studied in the field and which according to the aerial photograph ought to have the same soil condition, it is possible to deduce this condition from the air photo by means of photo interpretation. However, it is a condition that the soil boundaries and the soil mapping units in those parts are clearly visible on the photograph. This means, that this work can only be carried out in areas where over a large surface the same mapping units occur and of which a pedological reconnaissance map on a scale of $1: 100.000$ or smaller is to be made. Only in special cases can the method be applied to soil maps on a scale of $1: 50.000$. We have indicated a simple scheme in fig. 6. If an air-photo analysis has been made of the whole territory and in the shaded strips complementary field work has been carried out, and thus the above-mentioned conditions have been satisfied, then for the nonshaded strips an interpretation is sufficient. This actually is an interpolation. Therefore this method is called the pedological interpretation of aerial photographs according to the method of interpolation. When using this method, it should be realized that errors can easily occur. It is therefore advisable to do some checking in the field, at points where this seems most necessary. Thus, this method of air-photo interpretation opens up some perspectives in soil 


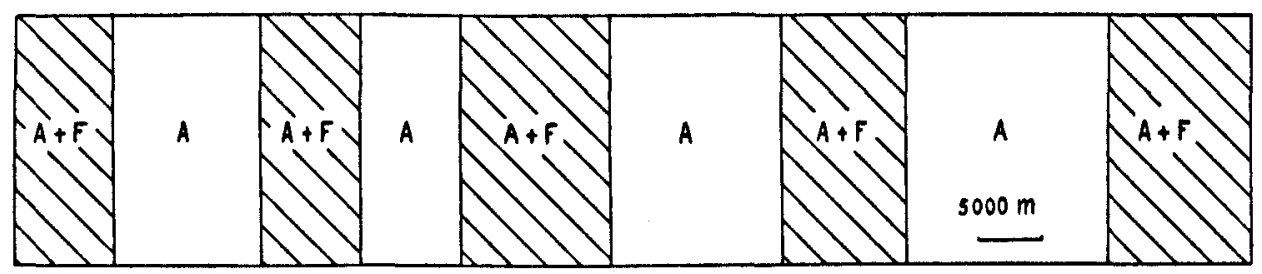

Fif. 6. Diagram showing the pedolocical photo intenphetation acconding to the METHOD of INTEnPolation. The areas indicated with $A+F$ are mapped by photo analysis in combination with field work; the areas indicated with $A$ are mapped by photo analysis only.

survey. It enables the soil surveyor to increase his output of work, without the quality of his research becoming less.

It is our impression that for this research about one sixth of the time required for an ordinary soil survey is needed.

The pedological interpretation according to the method of extrapolation is carried out in such a way that the photo interpreter can use his knowledge of aerial photographs and soil science also for such territories as have not been studied in the field at all, or only to a small extent.

In this case a general and pedological orientation research of a large area is concerned. For this kind of photo-interpretation a classification into simple land units which affords an insight into the physical soil condition of a large area must suffice. Though generally speaking this work is only of importance for thinly populated territories, the result is not less valuable. During some tours, of which the route can accurately be determined beforehand, the first pedological data can be collected. This research gives a general idea about the possibilities of the land development, on the basis of which the most suitable areas can be selected. A pedological photo-analysis combined with field and laboratory research can then be executed in these areas, if necessary by applying the aforementioned method of interpolation.

This method of extrapolation was applied by us for a survey of part of the South Coast of Dutch New Guinea. A great advantage is that large areas are excluded from further research, so that all the work and time can be devoted to a study of soils in areas of which favorable results may be expected. Mr. Frost (1952) has already pointed out this great advantage in connection with highway engineering. If before the second world war this method of research had been applied in Indonesia, some $90 \%$ of the time (according to Prof. Dr F. A. v. BaneN, former President of the Institute for Soil Research in Bogor) which has now been necessary for soil research, could have been saved. For large parts of the world this way of applying of the aerial photograph may become extremely important.

The above-mentioned methods must be developed by continued research; experience and knowledge is required from the users. It is therefore advisable to train oneself in the use of aerial photographs.

Aerial photographs, taken with modern cameras and elaborated with the latest instruments, have created new possibilities, which are important for soil and land classification and in many other fields. It should be borne in mind, however, that there are not only many possibilities, but also limitations to its 
use. The air-photo analysis and interpretation must be considered as means of which much may be expected, though not more than they can offer.

\section{REFERENCES}

ANonymous: A guide to pacific landforms and vegetation for use in photo interpretation. U.S. Naval Photogr. Intell. Centre, Washington, 1945.

Burinch, P.: The role of aerial photography when drafting schemes for underdeveloped countries. Netherlands Journal Agr. Sc. 1 (1953) 251-255.

Coвb, W. B. : in Amer. Assoc. Soil Survey Workers. Bull. IV, vol. 1, 1923.

Colweld, N. : Photogrammetric interpretation for civil purposes. In Manual of Photogrammetry, Washington Sec. Ed. (1952) 535-602.

Drabbe, C. A. v. Frytag : Aerial photographs and photo interpretation, Delft, 1951.

Eyk, J. J. v. D. : Soil mapping from aerial photographs. Phot. Eng. 18 (1953) 162-166.

- - and H. A. J. Hendriks : Soil- and land classification in the old coastal plain of Surinam. Neth. Journal Agr. Sc. 1 (1953) 278-298.

Frost, R. E. and K. B. Woons : Airphoto patterns of soils in the Western United States. Perdue Univ. U.S. Dept. of Commerce Techn. Div. Rep. no. 85, 1950.

- - : The airphoto-interpretation program of research and instruction at Perdue Univ. Phot. Eng. 18 (1952) 701-719.

LEwIS, A. B.: Landclassification for agricultural development. F.A.O. Development paper no. 18 , Rome, 1952.

PASTo, J. K. : Soil mapping by stereoscopic interpretation of air photos. Proc. Soil Sc. Soc. of America, 17 (1953) 135-138.

REEd, W. E. : Reconnaissance soil survey of Liberia. U.S. Dept. Agr., Agr. Inf. Bull. no. 66, Washington, 1951.

Simonson, R. W. : Statement, panel on accelerated surveying and mapping program. Phot. Eng. 18 (1952) 639-643.

Smit Siebenga, G. L. : On geomorphic and geologic analysis and interpretation of aerial photographs. Tijdschr. Kon. Ned. Aardr. Gen., Amsterdam LXV (1948) 692-700.

SмrTH, H. T. U. : Aerial photographs and their application, New York, 1943.

- - : Photo interpretation in applied earth science. Phot. Eng. 18 (1952) 418-428.

- - : Notes on recent literature relating to photo interpretation. Phot. Eng. 19 (1953) 675 etc.

Sork Survey Staff : Soil survey manual. U.S. Dept. Agr. Handbook no. 18, Washington, 1951.

Stephens, C. G. : Soil Surveys for land development. F.A.O. Agr. Studies no. 20, Rome, 1953.

Wreslander, A. E. and R. E. Storie : Vegetational approach to soil surveys in wild-land areas. Proc. Soil Sc. Soc. of America 17 (1953) 143-147.

Literature on the interpretation of aerial photographs may be found in : Manual of Photogrammetry, Washington, Sec. Ed. 1952.

SMrth, H. T. U. : Phot. Eng. 18 (1952) 418-428 and 19 (1953) 675 etc.

Frost, R. E. : Phot. Eng. 18 (1952) 701-719. 